\title{
Setting goals in chronic care: Shared decision making as self-management support by the family physician
}

Citation for published version (APA):

Lenzen, S. A., Daniels, R., van Bokhoven, M. A., van der Weijden, T., \& Beurskens, A. (2015). Setting goals in chronic care: Shared decision making as self-management support by the family physician. European Journal of General Practice, 21(2), 138-144. https://doi.org/10.3109/13814788.2014.973844

Document status and date:

Published: 01/06/2015

DOI:

10.3109/13814788.2014.973844

Document Version:

Publisher's PDF, also known as Version of record

Document license:

Taverne

Please check the document version of this publication:

- A submitted manuscript is the version of the article upon submission and before peer-review. There can be important differences between the submitted version and the official published version of record.

People interested in the research are advised to contact the author for the final version of the publication, or visit the DOI to the publisher's website.

- The final author version and the galley proof are versions of the publication after peer review.

- The final published version features the final layout of the paper including the volume, issue and page numbers.

Link to publication

\footnotetext{
General rights rights.

- You may freely distribute the URL identifying the publication in the public portal. please follow below link for the End User Agreement:

www.umlib.nl/taverne-license

Take down policy

If you believe that this document breaches copyright please contact us at:

repository@maastrichtuniversity.nl

providing details and we will investigate your claim.
}

Copyright and moral rights for the publications made accessible in the public portal are retained by the authors and/or other copyright owners and it is a condition of accessing publications that users recognise and abide by the legal requirements associated with these

- Users may download and print one copy of any publication from the public portal for the purpose of private study or research.

- You may not further distribute the material or use it for any profit-making activity or commercial gain

If the publication is distributed under the terms of Article $25 \mathrm{fa}$ of the Dutch Copyright Act, indicated by the "Taverne" license above, 


\title{
European Journal of General Practice
}

\section{Setting goals in chronic care: Shared decision making as self-management support by the family physician}

\author{
Stephanie A. Lenzen, Ramon Daniëls, Marloes A. van Bokhoven, Trudy van \\ der Weijden \& Anna Beurskens
}

To cite this article: Stephanie A. Lenzen, Ramon Daniëls, Marloes A. van Bokhoven, Trudy van der Weijden \& Anna Beurskens (2015) Setting goals in chronic care: Shared decision making as self-management support by the family physician, European Journal of General Practice, 21:2, 1-7, DOI: $10.3109 / 13814788.2014 .973844$

To link to this article: https://doi.org/10.3109/13814788.2014.973844

\section{曲 Published online: 26 Dec 2014.}

Submit your article to this journal 2

\section{Article views: 4496}

\section{Q View related articles $\sqsubset$}

View Crossmark data $₫$

Citing articles: 10 View citing articles $\asymp$ 


\title{
Background Paper
}

\section{Setting goals in chronic care: Shared decision making as self-management support by the family physician}

\author{
Stephanie A. Lenzen ${ }^{1,2}$, Ramon Daniëls ${ }^{1}$, Marloes A. van Bokhoven ${ }^{2}$, Trudy van der Weijden ${ }^{2}$ \\ \& Anna Beurskens ${ }^{1,2}$ \\ ${ }^{1}$ Research Centre for Autonomy and Participation for People with a Chronic Illness, Zuyd University of Applied Sciences, \\ Heerlen, the Netherlands, and ${ }^{2}$ Department of Family Medicine, CAPHRI School for Public Health and Primary Care, \\ Maastricht University, Maastricht, the Netherlands
}

KEY MESSAGE:

- Self-management goals should be set from a holistic perspective on the patient.

- Goal setting within self-management incorporates tailored assessment of patients' skills and motivation, as well as tailored support.

- Goal setting within self-management is a circular process in which patients and professionals need to be supported.

\begin{abstract}
Introduction: Self-management is considered a potential answer to the increasing demand for family medicine by people suffering from a chronic condition or multi-morbidity. A key element of self-management is goal setting. Goal setting is often defined as a moment of agreement between a professional and a patient. In the self-management literature, however, goal setting is regarded as a circular process. Still, it is unclear how professionals working in family medicine can put it into practice. This background paper aims to contribute to the understanding of goal setting within self-management and to identify elements that need further development for practical use.

Debate: Four questions for debate emerge in this article: (1) What are self-management goals? (2) What is necessary to accomplish the process of goal setting within self-management? (3) How can professionals decide on the degree of support needed for goal setting within self-management? (4) How can patients set their goals and how can they be supported?

Implications: Self-management goals can be set for different (life) domains. Using a holistic framework will help in creating an overview of patients' goals that do not merely focus on medical issues. It is a challenge for professionals to coach their patients to think about and set their goals themselves. More insight in patients' willingness and ability to set self-management goals is desirable. Moreover, as goal setting is a circular process, professionals need to be supported to go through this process with their patients.
\end{abstract}

Keywords: self-care, chronic disease, multi-morbidity, goals, primary health care, self-management, shared decision making, goal setting, action planning

\section{INTRODUCTION}

The number of patients with one or more chronic conditions being treated in primary care has increased steadily in recent years (1). Among the elderly worldwide, the prevalence of multi-morbidity is over $60 \%$ (2). Suffering from one or more chronic conditions has a great impact on daily life for people, leading to an expanding demand for health services and an increasing financial pressure on the health-care sector $(1,3)$. As family medicine is characterized as longitudinal and continuous, it is in a central position as regards the management of chronic conditions and multi-morbidity (4). Particularly multimorbidity is challenging to family medicine as clinical practice guidelines for different conditions are sometimes conflicting (5). Making shared decisions based on the patient's preferences, as well as on the different

Authors' contributions: SL and RD were responsible for writing the paper. AB, LvB and TvdW contributed to the manuscript design, planning, drafting, appraisal and editing.

Correspondence: Stephanie Lenzen, Research Centre for Autonomy and Participation for People with a Chronic Illness, Zuyd University of Applied Sciences, Nieuw Eyckholt 300, Box 550, Heerlen, the Netherlands. Email: stephanie.lenzen@zuyd.nl 
clinical practice guidelines and the physician's knowledge and expertise is a complex process (5).

Self-management, i.e. the degree to which a patient with a chronic condition is able and willing to control his or her daily life (6), is considered to provide benefits to chronically ill patients, as well as to the health-care system (6). It is believed to increase patients' power over and responsibility for their treatment process and promote their autonomy (6). Self-management support is defined as 'the actions that health professionals perform, tailored to the individual patient's needs and capabilities' (7). It is thought to enlarge the patient's belief in his or her ability to perform a certain behaviour (8). Therefore, many treatment guidelines for chronic conditions (e.g. for COPD) include self-management support (9).

Several authors recognize 'goal setting,' i.e. the agreement between health-care professionals and patients on a health-related goal (10), as a key element of self-management (support) $(10,11)$. As family medicine is defined as a person-centred discipline and as dealing with patients and their problems in their own life circumstances, individualized goal setting is strongly related to family medicine (4). Therefore, de Sutter et al., state that, 'family medicine is in a strategic position to help patients increase their ability and selfconfidence in managing chronic conditions [by setting] individual health related goals' (12). Family doctors, as well as practice nurses, appear to have difficulties implementing goal setting into their routine medical care (13). Information on how goal setting within self-management should be performed is, usually, absent from treatment guidelines.

Within the context of a large Dutch research project 'Interprofessional self-management support for patients with chronic diseases in primary care' (14), we gathered a great amount of frequently cited key literature about self-management and goal setting for patients with chronic diseases. While analysing the literature, four questions for debate came up about the concept of goal setting from the perspective of self-management. This paper aims to clarify ways to support goal setting within self-management in family medicine and to identify elements that need further development to bring self-management goal setting into practical use.
First, the concepts of self-management (support) and goal setting as defined in the literature will be reviewed. Then, four questions for debate will be presented and finally, implications for practice and research will be discussed.

\section{DEFINING THE CONCEPTS}

\section{Self-management}

Based on the Chronic Care Model, self-management is defined as 'the degree to which a patient with a chronic condition is able and willing to control his or her daily life.' Control is achieved through 'effective management of symptoms, treatment of physical, social and psychological disease consequences, and lifestyle adjustments' (15). This definition integrates the three varieties of self-management as described by Corbin and Strauss (1988): medical, social (role) and emotional self-management (16). These three types are frequently referred to in the self-management literature (3). In Table 1, the three forms of self-management are described and illustrated by an example of a 65-year old woman suffering from COPD.

\section{Self-management support}

Self-management support can be defined as 'the actions that health caregivers perform, tailored to each patient's needs and capabilities, with the aim of assisting and encouraging patients to become good managers of their chronic conditions' $(3,7)$. In the literature, there is consensus about the relevance of support for patients to become successful self-managers $(3,7)$. Although there is no generally accepted self-management support model, the '5-A model' (Assess, Advise, Agree, Assist, Arrange) of behaviour change counselling (see Table 2 for description and a case example) is internationally recognized as a systematic method of supporting selfmanagement (17). The model outlines the process that professionals can go through to support self-management. The model can be applied to medical, social and emotional self-management. In each of the five steps of the model, professionals and patients can use supportive tools or methods $(11,17)$.

Table 1. The three types of self-management (16) with a case example.

\begin{tabular}{lc}
\hline Type of self-management & Case example of a 65-year old woman with COPD \\
\hline $\begin{array}{l}\text { Medical self-management: Coping with symptoms and complying } \\
\text { with treatment measures. }\end{array}$ & $\begin{array}{c}\text { Learning to recognize an exacerbation and adjusting medication } \\
\text { accordingly. } \\
\text { Social (role) management: Adjusting one's behaviour in order } \\
\text { to maintain or adjust one's life roles. }\end{array}$ \\
$\begin{array}{l}\text { Emotional self-management: Dealing with emotional reactions } \\
\text { to a chronic condition, such as fear and depression, and coping }\end{array}$ & $\begin{array}{c}\text { Learning to deal with the fear of deterioration and the sadness that } \\
\text { with discomfort and disability. }\end{array}$ \\
\hline
\end{tabular}


Table 2. The '5-A model' of behaviour change (17) with case example.

\begin{tabular}{|c|c|}
\hline The '5-A model' steps & Case example of a 65 -year old woman with COPD \\
\hline $\begin{array}{l}\text { Assess: Determination of medical and motivational } \\
\text { conditions and the patient's current involvement in } \\
\text { self-management, own wishes and needs, willingness } \\
\text { to change, as well as current and desired level of } \\
\text { knowledge. }\end{array}$ & $\begin{array}{l}\text { The patient usually has exacerbations in autumn. She rarely visits a physician, but } \\
\text { she wants to improve her condition in order to be able to visit the playground } \\
\text { with her grandchildren. She is prepared to exercise to improve her condition and } \\
\text { is willing to learn if there are groups of COPD patients she can join for sporting. } \\
\text { She tells the physician that she finds it hard to cope with limitations, like not being } \\
\text { able to care for her grandchildren. }\end{array}$ \\
\hline $\begin{array}{l}\text { Advise: Patient education and communication of specific } \\
\text { information about health risks and the benefits of } \\
\text { particular changes. }\end{array}$ & $\begin{array}{l}\text { The physician informs her about the value of daily movement for improving } \\
\text { condition and about weight management in relation to COPD. }\end{array}$ \\
\hline $\begin{array}{l}\text { Agree: Collaborative goal setting and action planning } \\
\text { based on the patient's level of interest and confidence } \\
\text { in their ability to change. }\end{array}$ & $\begin{array}{l}\text { The patient and the physician agree on the patient's goals to improve her condition } \\
\text { and to learn how to arrange sufficient movement in daily life in order to be able } \\
\text { to visit the playground with her grandchildren again. They agree on a referral to a } \\
\text { physical therapist. } \\
\text { Furthermore, the patient sets a goal to learn to deal with the consequences of the } \\
\text { disease. The physician and the patient discuss several options to reach that goal } \\
\text { (e.g. patient support groups, referral to a psychologist). The patient decides to } \\
\text { postpone the decision over possible actions. She also decides not to focus on } \\
\text { weight management in this period. }\end{array}$ \\
\hline $\begin{array}{l}\text { Assist: Detecting and addressing any barriers that may } \\
\text { interfere with the patient's achievement of his or her } \\
\text { goals and supporting the patient in working on his or } \\
\text { her goals. }\end{array}$ & $\begin{array}{l}\text { The patient experiences difficulties in finding a physical therapist who offers group } \\
\text { sport activities for patients with COPD. The physician informs her about a website } \\
\text { where she can find sport groups for patients with COPD. }\end{array}$ \\
\hline $\begin{array}{l}\text { Arrange: Monitoring the patient in follow-up meetings } \\
\text { which are scheduled in a clear and timely manner. }\end{array}$ & $\begin{array}{l}\text { The physician and the patient agree to schedule a new appointment after finishing } \\
\text { physical therapy to evaluate her condition and to review if any actions for reaching } \\
\text { the goal to learn to cope with the disease are wished-for. The physician intends to } \\
\text { ask how she feels about weight management at that moment. }\end{array}$ \\
\hline
\end{tabular}

\section{Goal setting}

'Goal setting' is regarded a key element of self-management $(10,11,17)$. In primary care, the term 'collaborative goal setting' is used (11). Bodenheimer and Handley (2009) define 'collaborative goal setting' as 'a process in which health care professionals and patients agree on a health-related goal' (10).

Many authors agree that goal setting is a circular process $(18,19)$. Based on previous goal setting theories (20-22), Scobbie, Wyke and Dixon (2011) developed a process framework called the 'Goal setting and action planning practice framework' (19). It incorporates four phases in which patients and professionals cooperate, as described further in Table 3 (19).

\section{FOUR QUESTIONS FOR DEBATE}

Although literature about self-management and goal setting is widely available, it is still unclear how to combine these concepts and put them into practice. A better understanding of goal setting as part of self-management is necessary for professionals working in primary care to be able to support patients with chronic diseases in improving the self-management of their lives. We think that the following four questions are worth debating:

- What are self-management goals?

- What is necessary to accomplish the process of goal setting within self-management?

- How can professionals decide on the degree of support needed for goal setting within self-management?

- How can patients set their goals and how can they be supported?

\section{What are self-management goals?}

Although three types of self-management (medical, social and emotional self-management) can be distinguished, the literature shows a strong emphasis on medical selfmanagement goals (23). Goals collaboratively formulated by patients and their doctors, focus mainly on medication, physical activity and diet behaviour (24). In addition, these goals are often directed at biomedical outcomes,

Table 3. The 'goal setting and action planning practice framework' (19).

- Goal negotiation: Discussion of specific problems and potential goals

- Goal setting: Consideration of goal attributes like specificity, difficulty and compatibility with the patient's level of involvement

- Planning: Making action plans and coping plans for carrying out the goals

- Appraisal and feedback: Evaluation of action plan outcome and goal progress 
Table 4. Case example 'International classification of functioning' (29).

\begin{tabular}{ll}
\hline ICF domains & Case example of a 65-year old woman with COPD \\
\hline Function: Body functions or structures & $\begin{array}{l}\text { Increase depth of respiration } \\
\text { Increase muscle strength }\end{array}$ \\
Activity: Activities & $\begin{array}{l}\text { Being able to walk to the kindergarten and back } \\
\text { Being able to wash/dress and feed children }\end{array}$ \\
$\begin{array}{l}\text { Participation: Role performance } \\
\text { Environment: Physical, social and }\end{array}$ & $\begin{array}{l}\text { Being able to fulfill role as a grandmother } \\
\text { attitudinal environment }\end{array}$ \\
$\begin{array}{l}\text { Personal factors: Lifestyle, habits, } \\
\text { coping skills, etc. }\end{array}$ & Acceptance of limitations \\
\hline
\end{tabular}

such as 'lowering the level of HbA1c' for diabetic patients (12). Despite this focus on medical goals, there seems to be agreement upon the importance of emotional and social management goals $(25,26)$. Patients, particularly those who have recently been diagnosed with a chronic condition, often feel drawn to a search for meaning and a re-identification of the self, requiring them to find new ways to fulfil their roles in life (27). Because goals aiming at social and emotional management are barely represented in the literature, it is unclear how to formulate them. Moreover, it is debatable whether the three varieties of self-management can and should be separated from each other, as dealing with medical symptoms is clearly related to adjusting social roles. Making the link between medical goals and patients' social and emotional goals and explaining how these may be interrelated, is a challenge for the professional.

As an example, we refer to the previously introduced 65 -year-old woman who is diagnosed with COPD and experiences shortness of breath. Her medical symptoms could prevent her from going to the playground with her young grandchildren, and this could lead to an adjustment of her social role as a grandmother. She may feel sad about this. For other patients, it may have other drawbacks to cope with and invoke other emotions to deal with.

Thus, it is important that goals are set from a holistic perspective, tailored to each patient and that the interrelation of goals is made transparent. There are several frameworks that support the construction of a holistic perspective on the patient and his or her goals, for example, the structure of 'Comprehensive geriatric assessments (CGA)' tools may be supportive in setting holistic self management goals (28). The 'International classification of functioning, disability and health' (ICF) is a framework that has the potential to meet all requirements of a holistic approach (29). The ICF, developed by the World Health Organization (29), is recognized as a tool for classifying health, health-related domains and the interrelation of these domains (functions, activities and participation). It provides a uniform language for healthcare professionals worldwide (29). As an example, in Table 4 we again refer to the goals of the 65 -year-old woman who is diagnosed with COPD.
A recent scoping review by Constand and MacDermid (2013) about the applications of the ICF in goal setting practices shows that this framework is already frequently used as a practical tool for discussing patients' health status, functional status and related aspects (for example influencing environmental factors) (30). Thereby, as the ICF also directs attention to personal factors and the environment (such as involving the patient's family in managing disease consequences), it may support patients to get insight into their goals and into influencing factors $(29,30)$. Furthermore, the ICF might be helpful in organizing goals and matching appropriate interventions to the goals (30).

\section{What is necessary to accomplish the process of goal setting within self-management?}

Literature about goal setting often presents goal setting as more than just setting a goal at a particular moment, e.g. during a consultation or a home visit. Effective goal setting encompasses a broader process, which also involves negotiating, setting, planning and evaluating goals $(18,19)$. Goal negotiation-which involves discussion of any problems, exploration of patients' personal values, needs and capabilities, patient education and deliberation on optional goals-is considered a precondition for goal setting within self-management $(1,3,19)$.

In addition, some authors underline the importance of action planning and (proactive) coping planning after goal setting $(10,19,31)$. It includes planning about how to work on the established goals; specifically about who carries out each action as well as when, where and how often (10). Proactive coping is defined as 'anticipating and planning responses to obstacles that can occur during goal realization' (22). It involves identifying situations in which failures are likely to occur, and planning strategies on how to deal with these situations in advance $(22,32)$. Action planning and coping planning are approaches also used within problem-solving techniques (33). Patient-driven action plans and coping plans contribute to patient empowerment (12). Furthermore, as the nature of chronic diseases is dynamic and progressive, periodic goal evaluation through monitoring is important (17). 
Negotiation, setting, planning and evaluation of goals are phases recognized in the process framework by Scobbie, Wyke and Dixon (2011) (19) and in the '5-A model' (17) (in the phases of Agreeing, Assisting and Arranging). This is in contrast to the definitions that limit goal setting to the process of agreeing on a goal $(10,18)$. Explicitly highlighting goal negotiation, setting, planning and evaluation in the definition of goal setting within self-management may contribute to family doctors' awareness that goal setting is a circular and continuous process.

Besides, family doctors need to be able to communicate collaboratively with their patients throughout the whole goal setting process. A collaborative perspective and communication style, for example, is frequently used within cognitive behavioural techniques (34). In a randomized controlled trial Christiansen et al., (2010) indicate that cognitive behavioural problem-solving techniques might ensure goal realization for chronically ill patients (35). Moreover, other approaches for goal setting, like 'motivational interviewing' (a well-known counselling approach for behaviour change) (36), 'mental contrasting' (technique to imagine benefits and barriers for goal achievement) and 'forming implementation intentions' (technique to form if-then plans and specifying when, where and how) (37) can be incorporated in cognitive behavioural techniques, leading to higher goal commitment (35).

Because of the discussion, more attention should be devoted to developing tools, interventions and professional skills that are necessary to accomplish the entire goal setting process with the patient. To date, information on the effectiveness and feasibility of tools that support professionals working in primary care in completing the goal setting process (i.e. to negotiate, set, plan and evaluate goals) with their patients is hardly available (38).

How can professionals decide on the degree of support needed for goal setting within self-management?

Although goal-setting definitions address goal setting as a process, goal setting within self-management is also a skill that can be acquired by the patient $(6,10)$. Assisting patients in developing the skills required to set goals can be seen an integral part of self-management support $(7,17)$. Within self-management support, patients can be taught goal setting, with the aim of empowering them to continue goal setting for themselves (http://selfmanagementuk.org).

However, some patients do not wish to participate actively in goal setting or to self-manage. Some patients may prefer their family doctors to decide on their goals for them $(25,41)$. Furthermore, not every patient will be able to develop the capability to set self-management goals. Patient limitations in cognitive and communicative skills, limited insight into the symptoms and disabilities, and unstable emotional situations can limit participation in goal setting $(7,18)$. The literature presents several concepts that are related to patients' goal setting skills, like self-efficacy (20), sense of coherence (42) and autonomy (43). The first two are concerned with the belief and trust in one's ability to perform (self-management) behaviour. In particular, a person's sense of coherence is related to being able to cope proactively with tension and stressors, which is, as mentioned earlier, also part of the goal-setting process $(19,44)$. Moreover, patients' autonomy is often regarded as a requirement to manage chronic conditions (43). Decisional autonomy is needed to understand information and make decisions (set goals) and executive autonomy is needed to implement decisions (43).

Tools are available that measure all these concepts. However, it is unclear whether or how they could contribute to optimize goal setting within self-management. There seems to be a need for a clear overview of feasible tools that support family doctors and practice nurses in investigating the degree to which an individual patient can and wants to set self-management goals.

\section{How can patients set their goals and how can professionals support them?}

Goal setting is often presented as a collaborative process between a patient and a professional (10). However, one cannot ignore the recent rapid development of (webbased) self-management tools that patients can use independently from professionals, e.g. aiming at the preparation of a consultation. These tools offer opportunities for patients to think about goals themselves, educate themselves, monitor themselves, and make informed decisions and access support groups $(3,43)$. There are also tools that support patients to get in contact with peers and learn from one another, e.g. through the internet (44). For example, on the website 'Patients Like Me' (http://www.patientslikeme.com/), patients can connect with peers and share information about their chronic conditions, possibilities for treatment and coping strategies. As chronic conditions change over time, it is important and desirable for patients to be able to think about re-setting goals themselves, to proactively plan new actions and cope with new obstacles (17).

To facilitate this, we need more understanding of how patients themselves can identify and set goals, possibly in collaboration with others in their environment. Tools that might support this process should be easily accessible to patients, and they may decrease the demand for family medicine services. These developments again will require new skills from family doctors and practice nurses. Professionals should be able to coach their patients in using these patient tools in a tailored way (11). 


\section{IMPLICATIONS FOR PRACTICE AND RESEARCH}

Several practical implications derive from this discussion. Professionals working in family medicine may need to:

- Widen their perspective on patient goals and use a holistic framework that supports them to set goals together with patients on different levels (medical, social and emotional), and organize and interrelate goals.

- Develop skills and use tools that support the circular process of goal setting (negotiation, setting, planning, and evaluation).

- Use tools that support them to investigate patients' motivation and skills to set self-management goals.

- Coach patients to use supportive tools in a tailored way.

These recommendations are based on current literature on goal setting. As research in this area is still at an early stage, it is relevant to conduct more studies to:

- Empirically underpin feasibility and effectiveness of tools to support a holistic approach.

- Increase insight in which skills, assessments and tools are effective and feasible in the different phases of the goal setting process.

- Increase insight in the way family medicine professionals can individually support their patients to have an active role in goal setting.

Feasibility of tools and methods for goal setting is of major importance. Therefore, involvement of patients and professionals in their development is warranted.

\section{FUNDING}

This paper was funded by Stichting Innovatie Alliantie (PRO-3-36) and Zuyd University of Applied Sciences.

Declaration of interest: The authors report no conflicts of interest. The authors alone are responsible for the content and writing of the paper.

\section{REFERENCES}

1. Jones MC, MacGillivray S, Kroll T, Zohoor AR, Connaghan J. A thematic analysis of the conceptualisation of self-care, self-management and self-management support in the long-term conditions management literature. J Nurs Healthc Chronic Illn. 2011;3:17485.

2. Salive ME. Multimorbidity in older adults. Epidemiol Rev. 2012;35:75-83.

3. Lawn S, Schoo A. Supporting self-management of chronic health conditions: Common approaches. Patient Educ Couns. 2010;80:205-11.

4. WONCA Europe. The European definition of general practice/ family medicine 2011. Available at: http://www.woncaeurope. org/sites/default/files/documents/Definition\%203rd\%20ed\%20 2011\%20with\%20revised\%20wonca\%20tree.pdf (accessed 2 June 2014).

5. Boyd CM, Darer J, Boult C, Fried LP, Boult L, Wu AW. Clinical practice guidelines and quality of care for older patients with multiple comorbid diseases. J Am Med Assoc. 2005;294: 716-24.

6. Embrey N. A concept analysis of self-management in long-term conditions. Br J Neurosci Nurs. 2006;2:507-13.

7. Bodenheimer T, MacGregor K, Sharifi C. Helping patients manage their chronic conditions. Oakland, California: California HealthCare Foundation; 2005.

8. Battersby M, Van Korff M, Schaefer J, Davis C, Ludman E, Greene S, et al. Twelve evidence-based principles for implementing self-management support in primary care. Jt Comm J Qual Patient Saf. 2010;36:561-70.

9. National Institute for Health and Clinical Excellence (NICE). Chronic obstructive pulmonary disease: Management of chronic obstructive pulmonary disease in adults in primary and secondary care (partial update) 2014. Available at: http://www.nice.org. uk/Guidance/CG101 (accessed 25 June 2014).

10. Bodenheimer T, Handley MA. Goal-setting for behavior change in primary care: An exploration and status report. Patient Educ Couns. 2009;76:174-80.

11. Coleman M, Newton K. Supporting self-management in patients with chronic illness. Am Fam Phys. 2005;72:1503-10.

12. De Sutter A, De Maeseneer J, Boeckxstaens P. Empowering patients to determine their own health goals. Eur J Gen Pract. 2013;19:75-6.

13. Kruse R, Olsber J, Parker Oliver D, Shigaki C, Vetter-Smith $M$, LeMaster J. Patient-provider communication about diabetes self-care activities. Fam Med. 2013;45:319-22.

14. Fact sheet: Interprofessional self-management support for patients with chronic diseases in primary care [Internet]. Heerlen: Zuyd University of Applied Sciences, The Faculty of Health (the Netherlands). Available from: http://international. zuyd.nl/factsheet-selfmanagement (accessed 10 September 2014).

15. Wagner EH, Bennett SM, Austin BT, Greene SM, Schaefer JK, VonKorff $\mathrm{M}$. Finding common ground: Patient-centeredness and evidence-based chronic illness care. J Altern Complement Med. 2005;11:7-15.

16. Corbin J, Strauss J. Unending work and care: Managing chronic illness at home. San Francisco: Jossey-Bass; 1988.

17. Bodenheimer T, Grumbach K. Self-management support for people with chronic illness. In: Shanahan JF, Brown R, editors. Improving primary care-strategies and tools for a better practice. 1st ed. New York: The MacGraw-Hill Companies; 2007.

18. Rosewilliam S, Roskell C, Pandyan A. A systematic review and synthesis of the quantitative and qualitative evidence behind patient-centred goal-setting in stroke rehabilitation. Clin Rehabil. 2011;0:1-14.

19. Scobbie L, Dixon D, Wyke S. Goal-setting and action planning in the rehabilitation setting: Development of a theoretically informed practice framework. Clin Rehab. 2011;25:468-82.

20. Bandura A. Social foundations of thought and action: A social cognitive theory. Englewood Cliffs, New Jersey: Prentice-Hall, Inc.; 1986.

21. Locke EA, Latham G. Building a practically useful theory of goalsetting and task motivation: A 35-year odyssey. Am Psychol. 2002;57:705-17.

22. Schwarzer R. Self-efficacy in the adoption and maintenance of health behaviors: Theoretical approaches and a new model. In: Schwarzer R, editor. Self-efficacy: Thought control of action. Washington, DC: Hemisphere; 1992. pp. 217-43.

23. Wilson P, Kendall S, Brooks F. The expert patients programme: A paradox of patient empowerment and medical dominance. Health Soc Care Comm. 2007;15:426-38. 


\section{S. A. Lenzen et al.}

24. Brown VA, Bartholomew LK, Naim AD. Management of chronic hypertension in older men: An exploration of patient goal setting. Patient Educ Couns. 2007;69:93-9.

25. Davis GC, White TL. A goal attainment pain management program for older adults with arthritis. Pain Manag Nurs. 2008, 9:171-8.

26. Barlow J, Edwards R, Turner A. The experience of attending a lay-led, chronic disease self-management programme from the perspective of participants with multiple sclerosis. Psychol Health 2009;24:1167-80.

27. Rogers A, Kennedy A, Bower P, Gardner C, Gately C, Lee V, et al. The United Kingdom expert patients programme: Results and implications from a national evaluation. Med J Aust. 2008;189: 521-4.

28. Stuck A, Iliffe S. Comprehensive geriatric assessments for older adults. Br Med J. 2011. doi:10.1136/bmj.d6799

29. International Classification of Functioning, Disability and health (ICF). Available at: http://www.who.int/classifications/icf/en/ (accessed 10 April 2013).

30. Constand M, MacDermid J. Applications of the international classification of functioning, disability and health in goal setting practices in healthcare. Disabil Rehabil. 2014 23;36:1305-14.

31. Thoolen B, de Ridder D, Bensing J, Gorter K, Rutten G. Beyond good intentions: The development and evaluation of a proactive self-management course for patients recently diagnosed with type 2 diabetes. Health Educ Res. 2008;23:53-61.

32. Aspinwall L, Taylor S. A stitch in time: Self-regulation and proactive coping. Psychol Bull. 1997;121:417-36.

33. Stetson B, Boren S, Leventhal H, Schlundt D, Glasgow R, Fisher E, et al. Embracing the evidence on problem solving in diabetes selfmanagement education and support. SelfCare 2010;1:83-99.
34. Sage N, Sowden M, Chorlonton E, Edeleanu A. CBT for chronic illness and palliative care-a workbook and toolkit. Chichester: John Wiley \& Sons Ltd, The Atrium; 2008.

35. Christiansen S, Oettinger G, Dahme B, Klinger R. A short goalpursuit intervention to improve physical capacity: A randomized clinical trial in chronic back pain patients. Pain 2010;149: 444-52.

36. Miller WR, Rollnick S. Motivational interviewing: Helping people change. New York: The Guilford Press; 2013.

37. Oettingen G, Gollwitzer P. Strategies of setting and implementing goals. In: Maddux J, Tangney J, editors. Social psychological foundations of clinical psychology. New York: The Guilford Press; 2010:114-35.

38. Stevens A, Beurskens A, Koke A, van der Weijden T. The use of patient-specific measurement instruments in the process of goal-setting: A systematic review of available instruments and their feasibility. Clin Rehabil. 2013;27:1005-19.

39. Elwyn G, Edwards A, Kinnersley P. Shared decision-making in primary care: The neglected second half of the consultation. Br J Gen Pract. 1999;49:477-82.

40. Antonovsky A. The salutogenic model as a theory to guide health promotion. Health Promot Int. 1986;11:11-8.

41. Naik A, Dyer C, Kunik M, McCullough L. Patient autonomy for the management of chronic conditions: A two-component re-conceptualization. Am J Bioeth. 2009;9:23-30.

42. Eriksson M, Lindström B. Contextualising salutogenesis and Antonovsky in public health development. Health Promot Int. 2006;23:238-44.

43. Alpay $L$, van der Boog $P$, Dumaij $A$. An empowerment-based approach to developing innovative e-health tools for selfmanagement. Health Informatics Journal 2011;17:247-55. 